\title{
Differences between ITIL® V2 and ITIL® V3 with Respect to Service Transition and Service Operation
}

\author{
Roman Jašek, Lukáš Králík, Roman Žák, Alena Kolčavová \\ Tomas Bata University in Zlin \\ NadStranemi 4511, 76005 Zlin \\ Czech Republic
}

\begin{abstract}
This paper follows the article: Differences Between ITIL ${ }^{\circledR}$ V2 and ITIL ${ }^{\circledR}$ V3 with Respect to Service Strategy and Service Design. The main aim is to summarize the changes that relate to key publications, Service Transition and Service Operation. In conclusion, areevaluated the objectives of the current version of ITIL ${ }^{\circledR}$ v3 and the unofficial benefits. The purpose of these papers is to provide the necessary overview of the current situation in the field of IT management to facilitate and streamline the work of IT managers.
\end{abstract}

Keywords: ITIL, Service Operation, Service transition, Changes in ITIL, Life Cycle, Service Management. PACS: 07.05.Bx

\section{INTRODUCTION}

The basic principle of ITIL $₫$ v3 is based on the lifecycle management of IT services, respectively to control the value that IT provides to its customers. In central five books of the ITIL ${ }^{\circledR}$ v3, there are described 26 processes, many dozens of other activities from which many of them have the character of the whole process, 4 complex functions and approx. hundred roles that relate directly to the individual processes or for the entire service life-cycle. This is not the only difference from $\mathrm{v} 2$ :

- To understand the basic principles v2 was sufficient to read about 700 pages of key publications (service support and service delivery). The current version has around 1400 pages in 5 key publications of service lifecycle (Service Strategy, Service Design, Service Transition, Service Operation, and Continual Service Improvement).

- Individual elements of "best practice" in V3 are no longer puzzle of the "puzzle", as in V2, but pieces of construction kit of the "lego", which must be from a box of building blocks to choose the ones that are suitable for the type of construction that is created. In other words, not all elements of "best practice", which ITIL ${ }^{\circledR}$ v3 describes, are needed in every company.

- Processes are not primarily managed, but it is the life cycle of IT services. Therefore it would be more appropriate for ITIL ${ }^{\circledR}$ v3 not talk about implementation processes, roles, activities and functions, but about implementation of elements of "best practice".

\section{CHANGES IN KEY PUBLICATIONS}

Currently, there are large amount of companies that still holding longer stray ITIL v2. The general misconception is that ITIL v3 is a kind of update that does not bring any major changes. But it is quite the opposite. In addition to changing the number of key publications there is a change in the approach and orientation(Figure 1). 


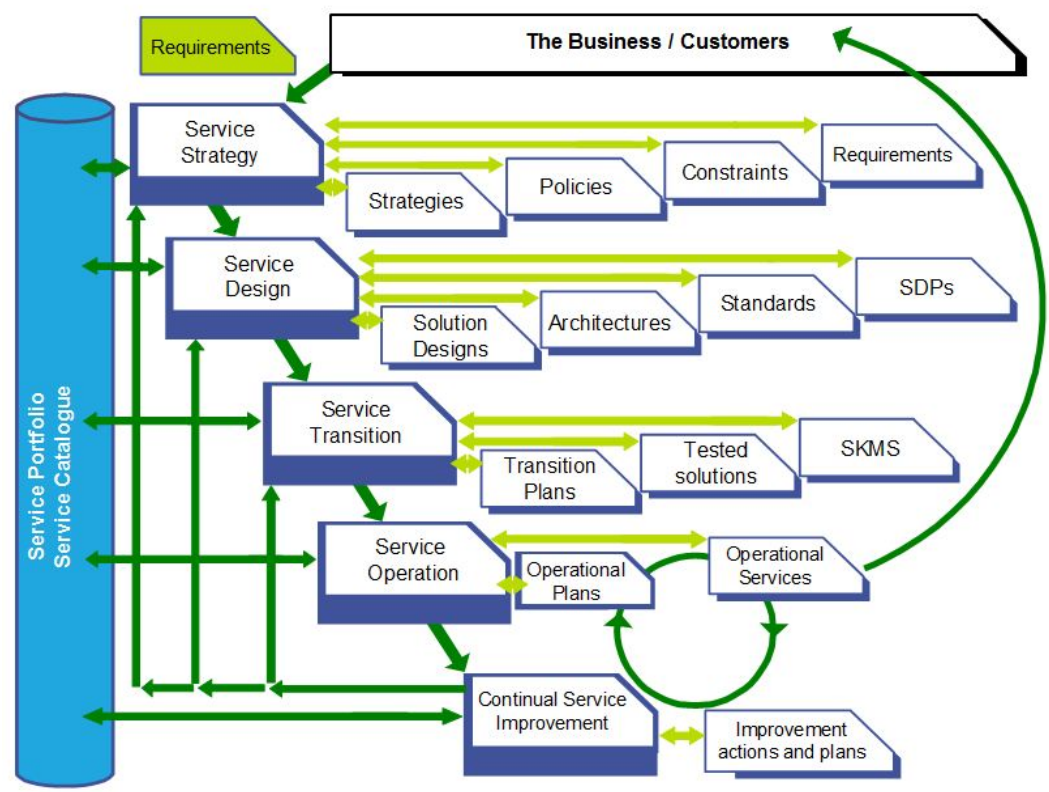

FIGURE 1. Conceptual model of ITIL $®$ v3

\section{Service Transition}

A very important change is the improvement of structuring and especially defining of relations between CMS (Configuration Management System) and SKMS (Service Knowledge Management System). CMS is part SKMS. While CMS contains configuration records, SKMS contains information about data assets (Figure 2).

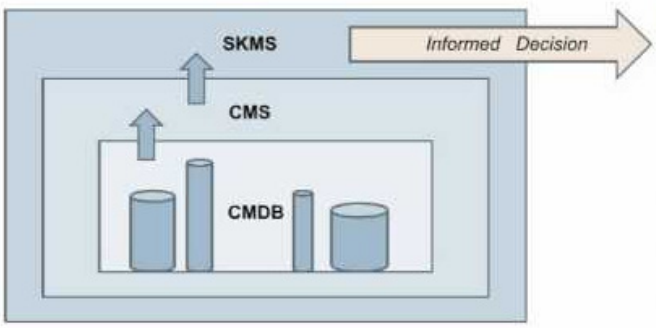

FIGURE 2. Relation between CMS and SKMS

Service Transaction Support and Planning process is intended to plan and coordinate the resources in order to deploy a major release within the predicted cost, time and quality estimates. This process is supplemented by detailed description of process.

The primary objective of Change Management process is to enable beneficial changes to be made with minimum disruption to IT services. The lifecycle of all changes is also controlled by this process. The new version of ITIL contains five levels of authorization for a model change - Innovation is in approval from Change Manager. Further, the workflow was updated with binding to RDM (Release and Deployment Management). Finally, an extension of CAB (Change Advisory Board) agenda contains change proposal.

Another process is called Service Asset and Configuration Management. It deals with maintaining information about configuration items required to deliver an IT service, including their relationships. This process contains following changes: Management of DML (Definitive Media Library), Actualization CMS and SKMS, Description of differences between Configuration Item and Service Asset and SW Asset Management.

To plan, schedule and control the movement of releases to test and live environments, there is Release and Deployment Management. The primary goal of this process is to ensure that the integrity of the live environment is protected and that the correct components are released. Newly, the process has only four phases and the workflow 
was changed in binding on CM (Change Management) process; thus, each release must be authorized through CM process. Moreover, DML is moved to SACM (Service Asset and Configuration Management.

Change Evaluation is determined to assess major changes, such as introduction of a new service or a substantial change to an existing service, before those Changes are allowed to proceed to the next phase in their lifecycle. Main innovations of this process lies in the change of confusing name of process and in different description and binding to CM. Workflow was also slightly changed.

Validation and Testing and Knowledge management remains without any major changes. The first is intended to ensure that deployed releases and the resulting services meet customer expectations, and to verify that IT operations is able to support the new service. The latter is designed to gather, analyze, store and share knowledge and information within an organization. The primary purpose of Knowledge Management is to improve efficiency by reducing the need to rediscover knowledge.

\section{Service Operation}

There is added completely new diagram showing the relation between service, Service Request, Request Fulfilment process, Request Model and Request for Change. Policies are supplemented for all processes.

Even in the service operation, most of processes were changed. There are only two processes, which remained without any changes - Service desk and Technical management. The first is intended to provide a Single Point of Contact ("SPOC") to meet the communication needs of both Users and IT employees. But it also is to satisfy both Customer and IT Provider objectives

Incident Management is process which solves the management of the lifecycle of all incidents and whose primary objective is to return the IT service to users as quickly as possible. New version contains actualization of workflow, addition of policy and procedure incident - problem matching.

Another process is Problem Management. It is designed to manage the lifecycle of all problems. The primary objectives of this process are prevention of Incidents from happening and minimization of the impact of incidents that cannot be prevented. Proactive Problem Management analyses Incident Records and uses data collected by other IT Service Management processes to identify trends or significant Problems. Changes lies in the Actualization of workflow - KEDB (Known Error Database).

Request Fulfillment serves to fulfil Service Requests, which in most cases are minor (standard) Changes (e.g. requests to change a password) or requests for information. Newly, there are binding between Service request and request models. Further, the new workflow appears with activities and steps involving decision-making points for request escalation. Finally, it contains changed description of service request and request models.

New workflow is also part of Access Management process. In this case, new workflow included inputs and bindings on IM (Incident Management). The process itself is intended to grant authorized users the right to use a service, while preventing access to non-authorized users. The Access Management processes essentially execute policies defined in Information Security Management. Access Management is sometimes also referred to as Rights Management or Identity Management.

Event management serves to make sure that CIs and services are constantly monitored, and to filter and categorize events in order to decide on appropriate actions. Actualization involves added filtering and rule engines, added policy and added diagram showing events hierarchy from infrastructure, services until enterprise processes.

Application Management is responsible for managing applications throughout their lifecycle. Newly, there is binding between Application Development and Application Management. Moreover, Change Case term is replaced by Use Case.

The last process is called IT Operations Management. It is determined to monitor and control the IT services and their underlying infrastructure. The process IT Operations Control executes day-to-day routine tasks related to the operation of infrastructure components and applications. This includes job scheduling, backup and restore activities, print and output management and routine maintenance.

\section{CONCLUSION}

Even though the ITIL $\mathbb{R}$ is updated to version 3 since 2011, there remains many companies and IT managers who still hold the ITIL ${ }^{\circledR}$ v2. It is not easy to say which of these versions is better. Every coin has two sides, so even here; the new version has its advantages (positives) and disadvantages (negatives). However the transition to the new version has its positives. Actually, the first and the largest is the fulfillment of the aims (Table 1) and officially declared benefits. Unofficially it is possible to meet with other benefits: 
- Unification of terminology (One of the advantages that applies almost always especially true for ITIL® v3);

- The only "methodology" for area of IT operation (The only real used "standard");

- The most detailed standard, easily available (Easy availability of publications and a variety of training);

- It is supported by the international standard for the certification of companies (ISO/IEC 20000:2011);

- It is supported by certifications at the level of individuals (Qualification scheme by APMG);

- $\quad$ "Mass" issue (Allows sharing of experience between companies and managers).

ITIL ${ }^{\circledR}$, without the reader aware, contains a variety of very useful methods, instruments and tools. Most of them are attachable in the whole range of ITL ${ }^{\circledR}$, not only partly in each publication, the life cycle phases or subprocesses.

Very serious issue that is often discussed is the fact that in the current version there is no guidance on how to properly implement ITIL®. Formal mention about implementation is in SD publication. But based on the experience of many managers these best practices are rather unfeasible. In contrast, the previous versions of ITIL $\mathbb{R}$ v2 contained implementation instructions in the "green book of ITIL" - ITSM Implementation Planning.

TABLE 1.Aims of ITIL® $\mathrm{v} 3$

\begin{tabular}{|c|c|c|}
\hline Aim & ITIL® v3 & Note \\
\hline Consistent roles across publications & $90 \%$ & $\begin{array}{l}\text { Improperly applied terminology confusing } \\
\text { readers - accountable vs. responsible. }\end{array}$ \\
\hline Restructuring of key publications & $100 \%$ & $\begin{array}{l}\text { All publications written uniformly. } \\
\text { Process chapters have a uniform structure. }\end{array}$ \\
\hline $\begin{array}{l}\text { Alignment of the ITIL } \AA \mathrm{v} 3 \text { with other } \\
\text { products from the Cabinet Office }\end{array}$ & $80 \%$ & $\begin{array}{l}\text { Solved only by links. } \\
\text { Processes for managing projects, programs } \\
\text { and portfolios are not taken into account. }\end{array}$ \\
\hline $\begin{array}{l}\text { A clear definition of roles and } \\
\text { responsibilities }\end{array}$ & $90 \%$ & $\begin{array}{l}\text { Not applicable to smaller organizations, } \\
\text { where the theoretical number of roles } \\
\text { exceeds the potential number of employees. }\end{array}$ \\
\hline $\begin{array}{l}\text { Clarification of the definitions of Product } \\
\text { Manager and Service Owner, Service } \\
\text { Catalog Manager in SO }\end{array}$ & $100 \%$ & Problem caused by ITIL $\AA$ v2. \\
\hline Redesign of content by DTP methodology & $80 \%$ & Done, but with lowercase names. \\
\hline
\end{tabular}

\section{ACKNOWLEDGMENTS}

This work was supported by Internal Grant Agency of Tomas Bata University in Zlin under the project No. IGA/FAI/2014/020 and project No. IGA/FAI/2014/031.

\section{REFERENCES}

1. KUFNER, Vladimír. ITIL V3, edice 2011: "Boží soud" nad ITIL v3?. DSM - data security management. 2012, č. 4, s. 6.

2. KUFNER, Vladimír. ITIL V3: Změny v klíčových publikacích. DSM - data security management. 2012, č. 2 , s. 7.

3. KUFNER, Vladimír. ITIL V3, edice 2011: Co je nového?. DSM - data security management. 2012, č. 1, s. 5. ISSN 12118737.

4. BUCKSTEEG, Martin. ITIL 2011. 1. vyd. Brno: Computer Press, 2012, 216 s. ISBN 978-80-251-3732-1.

5. ITIL continual service improvement [online]. 2nd ed. London: TSO, 2011, xi, 246 s. [cit. 2013-07-22]. Best Management Practice. ISBN 978-0-11-331308-2. Available from: http://www.best-management-practice.com

6. ITIL service transition [online]. 2nd ed. London: TSO, 2011, xii, 347 s. [cit. 2013-07-22]. Best Management Practice. ISBN 978-0-11-331306-8. Available from: http://www.best-management-practice.com

7. ITIL service design [online]. 2nd ed. London: TSO, 2011, xi, 442 s. [cit. 2013-07-22]. Best Management Practice. ISBN 9780-11-331305-1. Available from: http://www.best-management-practice.com

8. ITIL service operation [online]. 2nd ed. London: TSO, 2011, xi, 370 s. [cit. 2013-07-22]. Best Management Practice. ISBN 978-0-11-331307-5. Available from: http://www.best-management-practice.com

9. ITIL: service strategy [online]. London: Stationery Office, 2011, xii, 264 s. [cit. 2013-07-22]. ISBN 978-011-3310-456. Available from: http://www.best-management-practice.com/ 
AIP Conference Proceedings is copyrighted by AIP Publishing LLC (AIP). Reuse of AIP content is subject to the terms at: http://scitation.aip.org/termsconditions. For more information, see http://publishing.aip.org/authors/rights-and-permissions. 